\title{
Expert System Offer Solutions for Automated Telescope Dome, Imaging System and Focus
}

\author{
Hatem Abdel kader \\ Department of Information \\ System \\ Menoufia University \\ Menoufia, Egypt
}

\author{
Ibrahim Selim \\ Department of Computer \\ Science \\ Higher Technological Institute \\ 10th of Ramadan city, Egypt
}

\author{
Mona Mohamed \\ Department of Information \\ System \\ Higher Technological Institute \\ 10th of Ramadan city, Egypt
}

\begin{abstract}
Nowadays, weather consider the important component in many domains so, these domains use weather station to measure the parameters of weather through embedded sensors and view the measurements by using monitoring system which allow the user to make analysis about an obtained data of the weather Our work based on usage of weather station to measure certain parameters which effect on our telescope (mirror) which responsible for orbs vision in the space, and view the measurements through monitoring system to make analysis about these measurements to control closing and opening operations of shutter of the building and telescope ( mirror)in this building. These operations can operate by building expert system by using EXsys corvid software program and that system like human expertise through usage of knowledge base and inference engine .
\end{abstract}

Keywords: Weather Station, Expert System, Monitoring System, EXsys corvid

\section{INTRODUCTION}

We The weather and the climate are effect in many domains so, measuring of the weather parameters as temperature ,Humidity, Rainfall, Wind speed, Solar radiation intensity, dew point, Atmospherics pressures , etc.....; these parameters of the weather can measure by using weather station so, many domains important for them to use weather station as agriculture, because the measurement obtained through weather station which determine timing cropping through measure the certain parameters as :

$\checkmark$ Temperature

$\checkmark \quad$ Wind speed

$\checkmark$ Solar radiation intensity

By using sensors as optokopler sensor to measure wind speed, LM 35 sensor to measure temperature and intensitas LDR sensor to measure sun which embed in weather station ,the signals from sensors processed. through microcontroller to wind speed, temperature , and Solar radiation intensity and presented that transferred data via LCD display, and data transmitted to $\mathrm{PC}$ via receiver unit [1].

Although the weather station is important component ,the monitoring system also important which use to measure trends of different indicators depend on collected data and the monitoring important for viewing the disaster which determine the suitable action based on the disaster so, the monitoring provide sufficient information to decision makers which help in identify problems to choose suitable solution or action[2]; and important for the weather station which receive weather data from microcontroller embed in weather station and monitoring present weather data and help user to make analysis for data via GUI that authorized the user to treat with data .

We will use the data extract from weather station and send the data to monitoring system in dome building that obtain data in GUI figure.
Through GUI figure in the monitoring system we will send orders (signals) for opening or closing the shutter and mirror of dome, this signals receive by controller embed in shutter and mirror ; this operation depend on analysis make on weather data in monitoring system .

The weather become constitute hazard in the road and may causes accidents, so the monitoring system for the weather become safety for the road and other fields to observe and monitor the measurements of the weather[3].

So, we will build expert system instead of human to make suitable decision for closing and opening the shutter and mirror of dome's building depend on the analysis for weather data view in monitoring system by using GUI figure ;that expert system has user interface which help use to interact with the expert system and inference engine which aim expert to find suitable solutions and decision through knowledge base owned to expert system which has knowledge related to this domain .

\section{RELATED WORK}

Many researchers used the weather station in their domains as an important component to measure different parameters that had an effect on their different domains and used sensors embed in weather station to measure temperature, atmosphere pressure and relative humidity, an analogue output obtained from sensors convert to digital signals and processed by microcontroller that data act as data logged, data logged transfer to PC have GUI program [4]. And developed Automatic Weather Station (AWS) that measure Air temperature, relative humidity, dew point, wind speed, and rainfall, AWS consist of remote weather station and main weather station; that remote weather station measure factors through sensors connected to microcontroller and transmit data to main weather station which logged and data received through receiver unit connected to PC that PC has Matlab that present data via GUI that authorized the user to treat with data (analysis data and present it via Matlab) [5].

used remote sensors to measure dew point temperature, relative humidity, temperature, atmospherics pressures which displayed 
and show through weather monitoring [LCD display]or[display unit], the System used for weather monitoring had microcontroller which convert analogue output obtained by sensors to digital through ADC in microcontroller and data of the weather displayed via display unit and receiver unit had software used for forecasting to data view in weather monitoring for analysis [6].

There are 6 approaches for monitoring system which view the temperature of bee colony and how temperature of bee colony transfer to bee keeper and each approach can solve the drawbacks of the previous approach and the simplest approach is the first one which the data obtained on the site not in any where ,the monitoring can help beekeeper to manage honey bee colonies and observe temperature of bee colony and make analysis on the viewed temperature and determine suitable action or decision depend on that the analysis[7] .

Usage of expert system can help us in the work to make decisions which can solve the problem of timing for closing and opening automatic, the science of the expert system branched from AI which simulate human thinking who has expertise in the specific domain to solve any problems related to that specific domain through knowledge in the expert system for specific domain [8][9]

And the expert system can use in many domains as Diagnosis of Some Diseases in domain of Medicine as heart diseases ,the expert system can diagnosis the disease for the patient through symptoms and analyzes for patients to help expert system to choose the correct decisions for treatments through knowledge base owned for expert system [10,20-37]

And use in diagnosis of kidney diseases which the diagnose obtained from the computer is similar to the the diagnose given by an expert doctor in that certain area ,the system its knowledge base has 27 for kidney diseases which difficult to diagnose by human; the user can asked by the system and answer with Yes or No and depend on these answers the system diagnose the symptoms and its suitable treatment [11]

And other applications that expert system success as :

$$
\begin{array}{cl}
\checkmark & \text { Predicting } \\
\checkmark & \text { Diagnosing } \\
\checkmark & \text { Planning } \\
\checkmark & \text { Monitoring } \\
\checkmark & \text { Controlling }
\end{array}
$$

There are 3 parts for the expert system Knowledge base which has data to specific domain to solve the problem, Working memory which has specific data should be task and Inference engine aim to arrive to conclusions based on task data $[12,14-$ 25]

And used in other domain is business which propose a heuristics fuzzy expert system to indicate the price of the products [13-37].

\section{PROPOSED SYSTEM}

Our proposed system will develop through the following steps:

\subsection{Collection of data}

We collect data of the weather by weather station through embed sensors specify to parameters of the weather and take in our consideration certain parameters as temperature, humidity, wind direction, dew point.

\subsection{Monitoring system}

After the process of collection of data done through the weather station, the weather data view through monitoring system or PC which help in making accurate analysis for these weather data.

\subsection{System development}

We will build an expert system by using exsys corvid software that mimic human thinking and expertises which instead of human by making decisions for close or open operation of the shutter and mirror of dome's building that decisions make depend on the measurements of the data extract from weather station; the proposed system and any other system consist if knowledge base, inference engine and user interface

\subsection{System verification}

We will apply our expert System which responsible for decisions making on dome building.

\section{FUTURE WORK}

After apply our expert system on the dome building; the future work will be making forecasting for data extract from weather station among 3 years ago, and apply data for each year on our expert system individually to close or open shutter and mirror, and make analysis on the results obtain from decisions of the expert system for each other individually and take the observations of data for each year to make forecasting.

\section{REFERENCES}

[1] Muhammad, Helman. "WEATHER MONITORING STATION WITH REMOTE RADIO FREQUENCY WIRELESS COMMUNICATIONS." International Journal of Embedded Systems \& Applications 2.3 (2012).

[2] Fengler, Wolfgang, Ahya Ihsan, and Kai Kaiser. Managing Post-Disaster Reconstruction Finance. Vol. 4475. World Bank Publications, 2008.

[3] Miró, J. R., R. Veciana, and A. Sairouni. "The use of advanced meteorological tools for monitoring the Weather hazards in roads." 17th International Road Weather Conference, SIRWEC. 2014.

[4] Noordin, Kamarul Ariffin, Chow Chee Onn, and Mohamad Faizal Ismail. "A low-cost microcontroller-based weather monitoring system." CMU Journal 5.1 (2006): 33-39.

[5] Sharan, Roneel V. "Development of a Remote Automatic Weather Station with a PC-based Data Logger." International Journal of Hybrid Information Technology 7.1 (2014).

[6] Gouda, K. C., V. R. Preetham, and MN Shanmukha Swamy. "MICROCONTROLLER BASED REAL TIME WEATHER MONITORING DEVICE WITH GSM."Volume 3, Issue 7, July 2014.

[7] Kviesis, Armands, and Aleksejs Zacepins. "System Architectures for Real-time Bee Colony Temperature Monitoring." Procedia Computer Science 43 (2015): 86-94.

[8] Joseph, Giarratano, and Riley Gary. "Expert systems principles and programming." PWS Publishing Company 2 (1998): 321.

[9] Wielinga, Bob J., A. Th Schreiber, and Jost A. Breuker. "KADS: A modelling approach to knowledge engineering." Knowledge acquisition 4.1 (1992): 5-53.

[10] Soltan, R. A., M. Z. Rashad, and B. El-Desouky. "Diagnosis of Some Diseases in Medicine via computerized 
Experts System." International Journal of Computer Science \& Information Technology 5.5 (2013).

[11] Roventa, Eugena, and George Rosu. "The diagnosis of some kidney diseases in a small prolog Expert System." Soft Computing Applications, 2009. SOFA'09. 3rd International Workshop on. IEEE, 2009.

[12] Buchanan, Bruce G., and Reid G. Smith. "Fundamentals of expert systems." Annual review of computer science 3.1 (1988): 23-58.

[13] Hesami, Masoud, Hamid Eslami Nosratabadi, and Hamed Fazlollahtabar. "Design of a fuzzy expert system for determining adjusted price of products and services." International Journal of Industrial and Systems Engineering 13.1 (2013): 1-26.

[14] Berényi, Zsolt, and István Vajk. "Sensors and Intelligent systems."

[15] Turban, Efraim, and Louis E. Frenzel. Expert systems and applied artificial intelligence. Prentice Hall Professional Technical Reference, 1992.

[16] Biondo, Samuel J., ed. Fundamentals of expert systems technology: principles and concepts. Intellect Books, 1990.

[17] Dym, Clive L., and Raymond E. Levitt. Knowledge-based systems in engineering. McGraw-Hill Book Company, 1991.

[18]Rauch-Hindin, Wendy B. "Artificial intelligence in business, science, and industry. Vol. I: Fundamentals." (1986).

[19] Rauch-Hindin, Wendy B. "Artificial intelligence in business, science, and industry. Vol. I: Fundamentals." (1986).

[20] Cragun, Brian J., and Harold J. Steudel. "A decision-tablebased processor for checking completeness and consistency in rule-based expert systems." International Journal of ManMachine Studies 26.5 (1987): 633-648.

[21] Yahia, M. E., et al. "Rough neural expert systems." Expert Systems with Applications 18.2 (2000): 87-99.

[22] Michie, Donald, ed. Introductory readings in expert systems. Vol. 1. CRC Press, 1982.

[23] Bobrow, Daniel G., Sanjay Mittal, and Mark J. Stefik. "Expert systems: perils and promise." Communications of the ACM 29.9 (1986): 880-894.

[24] Bobrow, Daniel G., Sanjay Mittal, and Mark J. Stefik. "Expert systems: perils and promise." Communications of the ACM 29.9 (1986): 880-894.

[25] Natke, Hans Günther, and Czes A. Cempel. Model-aided diagnosis of mechanical systems: fundamentals, detection, localization, and assessment. Springer-Verlag New York, Inc., 1997.

[26] Tamer Cavusgil, S., and Cuneyt Evirgen. "Use of expert systems in international marketing: an application for cooperative venture partner selection." European Journal of Marketing 31.1 (1997): 73-86.

[27] Grzymala-Busse, Jerzy W. Managing uncertainty in expert systems. Vol. 143. Springer Science \& Business Media, 1991.

[28] Davis, Randall. "Expert systems: where are we? and where do we go from here?." AI magazine 3.2 (1982): 3.

[29] Mockler, Robert J., and D. Dorothy G. Dologite. An Introduction to expert systems: Knowledge-based systems. Macmillan Publishing Company, 1992.

[30] Laurini, Robert, and Derek Thompson, eds. Fundamentals of spatial information systems. Vol. 37. Academic press, 1992.

[31] Nowakowska, Maria. "Fundamentals of expert systems: I. Judgements formation and problems of description." Mathematical Social Sciences 9.2 (1985): 93-171.

[32] Turban, Efraim, J. Aronson, and Ting-Peng Liang. Decision Support Systems and Intelligent Systems 7 “” Edition. Pearson Prentice Hall, 2005.

[33] Rangaswamy, Arvind, et al. "Developing marketing expert systems: An application to international negotiations." The Journal of Marketing (1989): 24-39.
[34] Swartout, William R., and Stephen W. Smoliar. "On making expert systems more like experts." Expert Systems 4.3 (1987): 196-208.

[35] Berry, Dianne C., and Donald E. Broadbent. "Expert systems and the man-machine interface." Expert systems 3.4 (1986): 228-231.

[36] Cowan, Robin. "Expert systems: aspects of and limitations to the codifiability of knowledge." Research Policy 30.9 (2001): 1355-1372.

[37] Kusiak, Andrew, and Jaekyoung Ahn. "Intelligent scheduling of automated machining systems." Computer Integrated Manufacturing Systems 5.1 (1992): 3-14. 